\title{
THE STUDY OF A CLINE
}

\author{
AMATHES GLAREOSA ESP. AND ITS MELANIC \\ F. EDDA STAUD (LEP.) IN SHETLAND
}

H. B. D. KETTLEWELL

Genetics Laboratory, Department of Zoology, University of Oxford

R. J. BERRY

M.R.C. Experimental Genetics Research Unit, University College, London, Gower Street, W.C. 1

\section{INTRODUCTION}

Received 15,iv.6!

IN the previous paper the occurrence of melanism in Lepidoptera in the Shetland Islands has been reviewed and the theoretical interest of studying the factors which contribute to the maintenance of melanic forms in so many species in this group has been set out (Kettlewell, 196ra). It has also been suggested that for practical reasons, the moth Amathes glareosa Esp. with its distinct melanic form edda would be suitable material for investigating the factors contributing to nonindustrial melanism. This paper and the one that follows give an account of the work on this insect carried out in Shetland in the summers of 1959 and 1960 .

Until recently knowledge relating to $A$. glareosa was limited to the casual observations of collectors, many of whom visited Unst, the northernmost main island of the Shetland group, for the specific purpose of catching (among other things) f. edda. This form of the moth was not known to occur elsewhere. $F$. typica, however, had been reported from Dunrossness on the south Shetland mainland. Hence the original problem was the relatively uncomplicated one of discovering why $A$. glareosa was largely replaced by a melanic form on Unst, an island 12 miles long by 6 wide. However, it soon became apparent that the situation was more complex than originally thought.

The first step consisted therefore of studying the structures of the two populations: at Baltasound on Unst in the north, and at Dunrossness in the south Shetland mainland. These preliminary investigations in 1959 were combined with a study of the natural history of the species. Dunrossness is only about $5^{\circ}$ miles to the south of Baltasound as the crow flies, but here the population of the moth was thought to be entirely composed of the typical form similar to that found over the mainland of Britain. In I959 we sampled the populations and made the discovery that while $f$. edda occupied a frequency of 97 per cent. $( \pm 0.34)$ at Baltasound ( $f$. edda $2462: f$. typica 77$)$, it also occurred at a frequency of 3 per cent. at Dunrossness in the south $(f$. edda $3: f$. typica 96). Moreover, a small sample of 23 moths caught at Hillswick, which is situated about midway between the two, showed that here the 


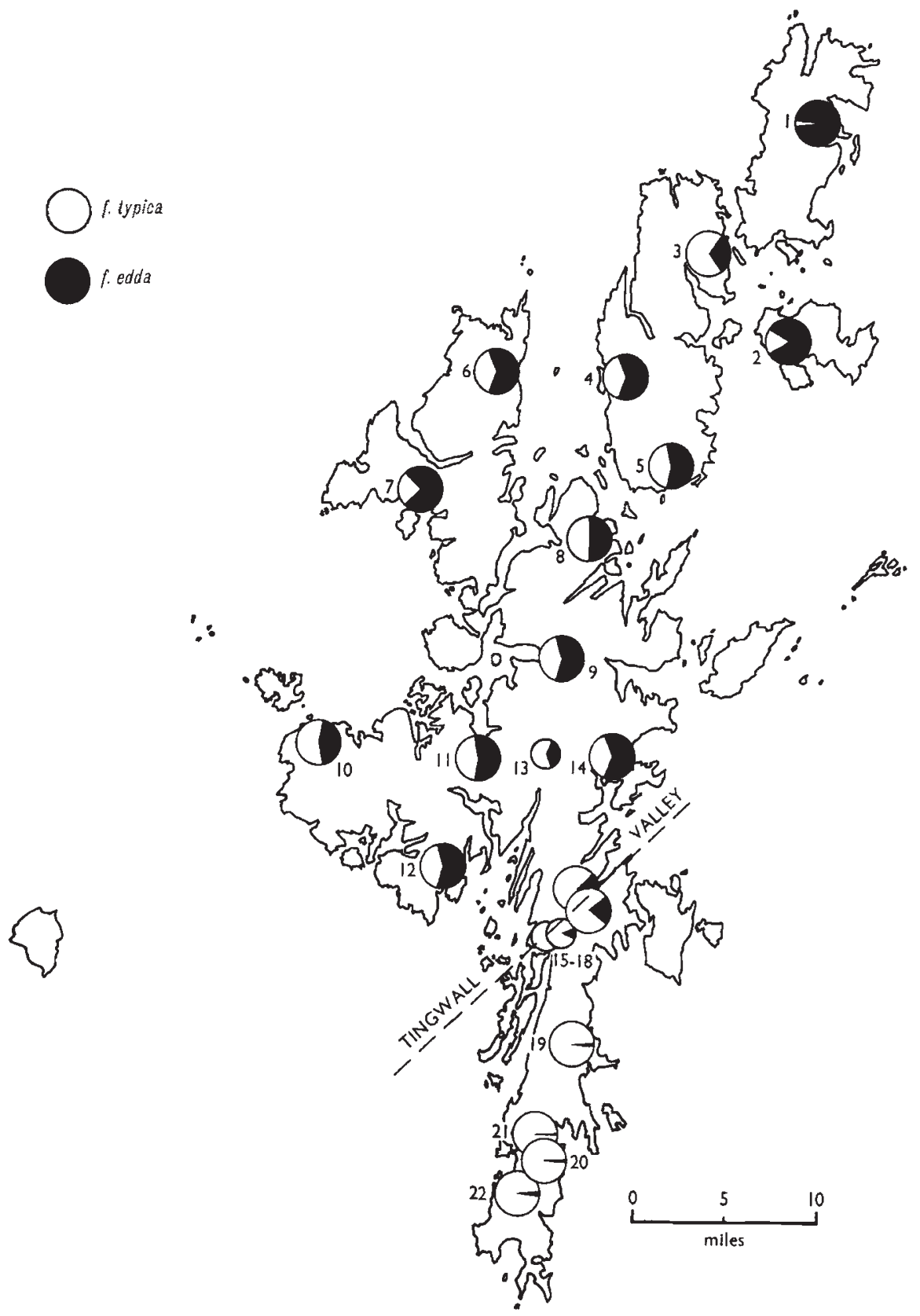

FIG. 1.-A frequency map of Amathes glareosa and its melanic form edda, comprising 20,000 records from 22 localities in Shetland. The numbers refer to the locations listed in table I. 
population was 83 per cent. $f$. edda ( $f$. edda I 9: $f$. typica 4$)$. Hence it was clear that the species seemed to be dimorphic throughout the length of Shetland, and our study was not merely concerned with the replacement of $f$. typica by $f$. edda over the limited area of Unst, but also with the co-existence of the two forms over the whole of the Shetland Isles.

The account that follows is of our investigation of the distribution of the frequencies throughout Shetland in 1960.

\section{METHODS OF INVESTIGATION}

The Shetland Islands are situated about one hundred miles to the north of the mainland of Scotland. The group is 54 miles in length from north to south and comprises three main islands, Unst, Yell and Shetland Mainland separated by two sounds, each approximately half a mile in width (see fig. I). There are about a hundred smaller islands at distances of a few hundred yards to 27 miles from the main group (viz. Fair Isle). The plan was to investigate the composition of the populations at as many places as possible throughout the Shetland Isles. The minimum sample envisaged was fifty specimens from each place. Although the majority were considerably larger than this a few were smaller, and all except the smallest ones have been included in the results (table $\mathrm{r}$ ).

The technique employed was to take samples of the population by means of mercury vapour light traps. Whenever possible the electricity supply was taken from crofts, but when not available (neither Yell nor Fetlar have mains electricity), portable generators were used. It has been shown in the case of Biston betularia $\mathrm{L}$. that both the typicals and the melanic mutants are attracted equally to light by comparing the proportions of those which were attracted to virgin females with those which came to light (Kettlewell, 1955). We had no reason to suppose that the two forms of $A$. glareosa, once they had taken flight, behaved otherwise.

It is perhaps worth emphasising a point already made, that the two forms of the moth are completely distinct, and there is rarely any difficulty in distinguishing the two (plate II, fig. I, in Kettlewell, I $961 a$ ). The only times any doubts arose were with very worn specimens, but they could always be assigned to their correct phenotype by reference to the colour of the underside of the body. In regions where a low frequency of $f$. edda occurred, such as Dunrossness, south Shetland, many of the melanics were rather lighter and browner in wing colour and more variable in pattern than in places with a higher incidence. These specimens were almost certainly heterozygous for the $e d d a$ gene, but can be referred to $f$. edda without hesitation. The Orkney and Fair Isle specimens fall into this same category where the edda frequencies (in small samples) are I 5 per cent. (edda 3 ; typica I7) (Ffennell, I96r) and 27 per cent. (edda I5; typica 40) (Hardy, I96I) respectively. A few specimens caught on Shetland could not be properly classified as $f$. typica nor $f$. edda. As the appearance of these 
specimens was fairly uniform among themselves, they may well represent another genotype. They have not so far been studied further.

Approximately 20,000 individuals were trapped and examined. The majority of these were caught at the two centres of the experimental work to be described in the following paper (Kettlewell, $1961 b)$. These were Baltasound in the north and Dunrossness in

TABLE I

Constitution of population samples of Amathes glareosa ( from north Shetland to south)

\begin{tabular}{|c|c|c|c|c|c|c|}
\hline \multirow{2}{*}{\multicolumn{2}{|c|}{ Area }} & \multicolumn{3}{|c|}{ Numbers caught } & \multicolumn{2}{|c|}{ Typica } \\
\hline & & Typica & Edda & Total * & Phenotype & Gene \\
\hline \multicolumn{2}{|l|}{ Unst } & & & & & \\
\hline \multicolumn{2}{|c|}{$\begin{array}{l}\text { 1. Muckle Heog (Baltasound) } \\
\text { Fetlar }\end{array}$} & 292 & 10359 & 10651 & $2 \cdot 7$ & $16 \cdot 4$ \\
\hline \multicolumn{2}{|c|}{$r_{e l l}^{2 .}$ Tresta } & 34 & 162 & 196 & $17 \cdot 3$ & $4^{1 \cdot 6}$ \\
\hline \multicolumn{2}{|c|}{ 3. Gutcher . . } & $\begin{array}{r}3^{8} \\
139\end{array}$ & $\begin{array}{r}15 \\
224\end{array}$ & $\begin{array}{r}54 \\
364\end{array}$ & $\begin{array}{l}70 \cdot 4 \\
38 \cdot 2\end{array}$ & $\begin{array}{l}83 \cdot 9 \\
61 \cdot 8\end{array}$ \\
\hline \multicolumn{2}{|l|}{ North Mainland } & 23 & 29 & 54 & $4^{2} \cdot 6$ & $65 \cdot 3$ \\
\hline 6. North Roe. & . & 29 & 47 & 77 & $37 \cdot 7$ & $6 \mathrm{I} \cdot 4$ \\
\hline $\begin{array}{l}\text { 7. Hillswick . } \\
\text { 8. Mossbank. }\end{array}$ & $\dot{r}$ & $\begin{array}{l}21 \\
58\end{array}$ & $\begin{array}{l}66 \\
6 \mathrm{I}\end{array}$ & $\begin{array}{r}87 \\
110\end{array}$ & $\begin{array}{l}24 \cdot 1 \\
48 \cdot 7\end{array}$ & $\begin{array}{l}49 \cdot 1 \\
60 \cdot 8\end{array}$ \\
\hline 9. Voe & . & 63 & 90 & 153 & $41 \cdot 2$ & $64 \cdot 1$ \\
\hline 10. Sandness . & . & 119 & 95 & 214 & $55^{\cdot 6}$ & $74 \cdot 6$ \\
\hline 11. Aith . & . & 61 & 74 & 139 & $43 \cdot 9$ & $66 \cdot 3$ \\
\hline 12. Reawick . & . & 39 & 57 & $9^{6}$ & $40 \cdot 6$ & $63 \cdot 7$ \\
\hline 13. Kergord & . & 14 & 9 & 23 & $60 \cdot 9$ & $78 \cdot 0$ \\
\hline \multicolumn{2}{|c|}{ Tingwall Valley: North Border } & 22 & 34 & $5^{\breve{8}}$ & $37 \cdot 9$ & $6 \mathrm{I} \cdot 6$ \\
\hline 15. Catwalls (Gott) & . & 102 & 33 & ז35 & $75^{\cdot 6}$ & $86 \cdot 9$ \\
\hline \multicolumn{2}{|c|}{$\begin{array}{l}\text { 16. Scalloway 'S } \\
\text { Tingwall Valley: South Border }\end{array}$} & $3^{8}$ & 0 & 47 & $80 \cdot 9$ & $89 \cdot 9$ \\
\hline \multicolumn{2}{|c|}{ 17. Braewick (Dales Voe) } & 27 & 4 & 31 & 87. & \\
\hline 18. Burn of Dale (D & ales Voe) & 121 & 33 & 154 & $78 \cdot 6$ & $88 \cdot 7$ \\
\hline \multicolumn{2}{|l|}{ Dunrossness. } & & & & & \\
\hline 19. Cunningsburgh & . & 96 & 3 & 99 & $97^{\circ} \mathrm{O}$ & $98 \cdot 5$ \\
\hline 20. Boddam & 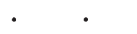 & 4364 & 85 & 4449 & $98 \cdot 1$ & $99^{\circ} \mathrm{o}$ \\
\hline 21. Levenwick & . & 173 & 2 & 175 & $98 \cdot 9$ & 99.4 \\
\hline 22. Scousburgh & . & 280 & 10 & 290 & $96 \cdot 6$ & $98 \cdot 3$ \\
\hline
\end{tabular}

* This includes I I specimens which were classified as intermediate, and may represent another genotype.

the south. Between these sites, samples were taken at a further 17 places. Trapping was continued in each locality until the sample totalled 50 or more or the exigencies of the British tourist season compelled removal. This means that in some places the sample was caught over a period of several days, often from more than one trapping site. The choice of site was usually restricted by the availability of the electricity supply, but in no instance were the sampling points in any one locality more than two miles apart. Successive samples from the same place taken at a later date showed slight but 
consistent increases in the proportion of $f$. typica (Kettlewell, $\operatorname{Ig} 6 \mathrm{I} b$ ), which undoubtedly biased the results to a small extent from different places. It does not, however, affect the over-all interpretation.

\section{RESULTS: DISTRIBUTION OF GENE FREQUENCIES}

The constitution of the population samples from different places enables the proportion of both forms and the frequencies of the edda and typica genes to be calculated, assuming the former to be dominant (table I). It is clear from the table that there are three general groupings: firstly on the two northernmost islands of Unst and Fetlar f. edda predominates; secondly on Yell and north Mainland the two forms of the moth are in approximate equality, ranging from about 40 to 60 per cent.; and thirdly, south of a line running just north of the two main towns, Lerwick and Scalloway, $f$. edda becomes rare. The main exception to this general picture is provided by the highly anomalous sample taken in Gutcher, in the northeast of Yell. There is at present no explanation for this population. The sample was taken on two successive nights, and on both the proportion of f. edda : f. typica was exactly the same. This site obviously should be re-investigated, but meanwhile it remains an exceptional locality.

Another place where a high frequency of $f$. edda is at first sight unexpected is Hillswick. However, the high proportion of $f$. edda found here fits into a trend such that the frequency of $f$. edda increases towards the sea, and Hillswick is on a promontory. The opposite trend is exemplified by the figures for Kergord. Kergord is a watershed on the central hills of Mainland, and is in fact as far from the sea as it is possible to get in Shetland. Despite the fact that Kergord is only 5 miles over the hills from Aith, which is on a sea loch, the frequency of $f$. edda is over Io per cent. less than at Aith. Previously collectors have reported that $f$. typica was commoner on the top of hills in Unst. We ourselves have no data on this point, but it is possible that at slightly higher altitudes, where on many evenings the hills are enveloped in clouds, visual predation would not take place at the same degree of intensity as in the clear atmosphere nearer sea level.

By making a series of approximate measurements of the distances of places apart, and ignoring minor effects, such as the distance from the sea, it is possible to plot a curve of gene frequency along the land distance in Shetland (fig. 2). Measurements were made of the shortest distances overland from one sampling centre to another. This graph shows both the gene frequency and the phenotype frequency in different areas.

The incidence of $f$. edda remains high over the whole of the northern half of Shetland, falling but gradually (4o per cent. in 45 miles) in a southerly direction. In the south Mainland where its frequency is low, the rate of change is even less ( 2 per cent. in 12 miles), being only 3 per cent. as far north as Cunningsburgh. It will be seen from fig. 2, however, that a different state of affairs exists in the intervening region. 
Here the phenotype frequency of $f$. edda drops 35 per cent. in about 8 miles, although the rate of change of gene frequency in the same area is proportionately less. Now there are two possible explanations of a situation such as this: either the average conditions in the north favour one form and in the south the other and between them there exists free gene flow; or there is an ecological gradient divided by some physical barrier which limits mixing between the two forms. It is possible that in the present case both factors contribute. It is certainly correct to interpret this central area as a boundary region. We were able to detect certain minor ecological differences between the north and the south of this boundary, and these are discussed later. However, there is a physical feature running through the middle of this area which might act as a barrier. This is the Tingwall Valley

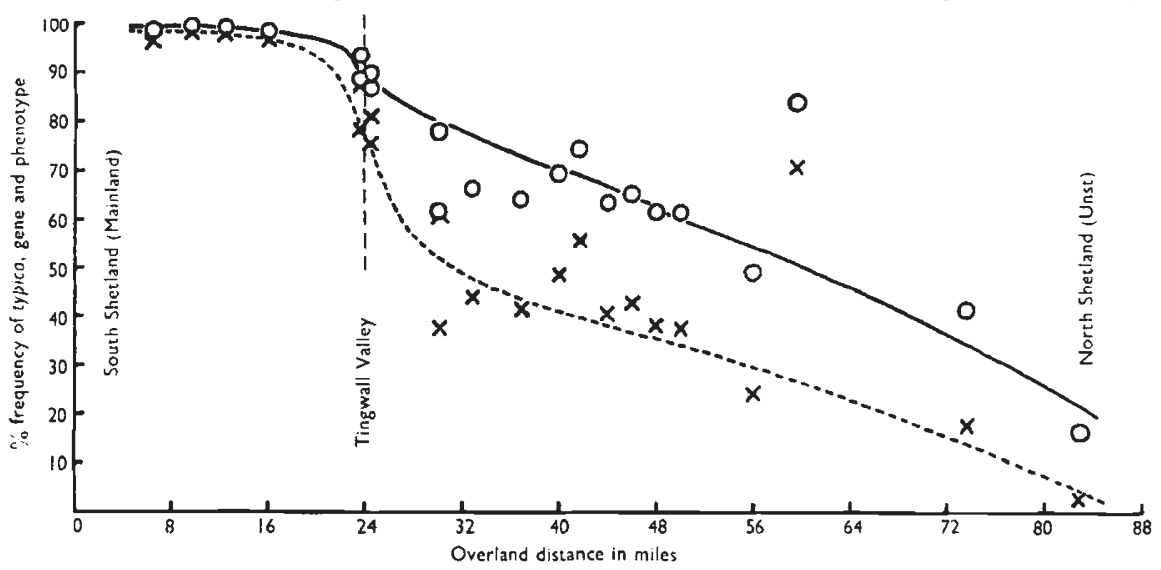

FIG. 2.-Decline in frequency of wild type Amathes glareosa and replacement by $f$. edda with distance northwards in Shetland. Phenotype frequencies are represented by $\mathrm{X}$, gene frequencies by $\mathrm{O}$. The dotted line shows the cline in phenotype frequency, the continuous line that in gene frequency.

which runs from southwest to northeast across the island, and varies from one to two miles in width. It consists of fertile farm land quite unsuitable for the requirements of $A$. glareosa. Samples taken on the north side of this valley showed violent fluctuations in frequency from day to day (Kettlewell, I $96 \mathrm{I} b$ ) and it can be said with a fair degree of confidence that this feature is likely to be a partial barrier and contribute to the boundary conditions. The significance of this is discussed in the following paper.

\section{DISCUSSION}

In the discussion that follows it will be assumed that the dimorphism in $A$. glareosa is in a balanced state. Although it is theoretically possible that one of the forms is in the process of spreading, it is unlikely. Evidence on this point would necessitate extensive sampling over a number of years. It can be stated that in 1959 and I $960 *$ the proportions of the two phenotypes were the same at Dunrossness, Hillswick 
and Baltasound, within the limits of sampling error. However, the environment in Shetland must have remained substantially the same since the last Ice Age, and it is a priori improbable that an advantageous mutation has only recently spread, the more so because of the existence of the same polymorphism in both Fair Isle and the Orkneys. It seems reasonable to assume that the observed composition of the species is stable.

A cline may be the result of a phenotype being at an advantage in one part of a continuous range of a species, while in another it is at a disadvantage. The extremes of the cline in A. glareosa are Baltasound ( $f$. edda 97 per cent.) and Dunrossness ( $f$. edda 2 per cent.). It is between these two places, where neither form is at a great advantage and both forms co-exist, that is our concern here.

The form of any cline is determined by the interplay of two factors:

I. Random migration serving to keep the populations mixed.

2. Selection tending to decrease the incidence of one or the other form.

An analysis of any specific cline must take account of both these agents. It is unlikely that $A$. glareosa actively migrates very far, but in the high wind conditions of Shetland, it may well be involuntarily blown some distance on occasions. The effect of natural selection and habit differences is dealt with more fully in the following paper (Kettlewell, ig6r $b$ ).

The mathematical theory of a cline has beeen developed by Fisher (1950) and Haldane (1948). Fisher considers a situation involving no dominance, which is of no concern here. Haldane takes the relevant case in which a dimorphism is determined by an autosomal dominant gene and its allelomorph. $\mathrm{He}$ analyses the situation when the range of the species (which he assumes to be plane and infinite) is sharply divided into two portions, such that the recessive homozygote has a fitness $I+K$ times that of the other genotypes on one side of the boundary, and $\mathrm{I}-k$ on the other. Haldane makes a number of reasonable assumptions in order to carry out this analysis: equal density of the species throughout the area; a single annual generation; random migration, although not necessarily equal in all directions; selection occurring at the point of breeding rather than birth; random mating; and a population in equilibrium. The essence of the calculation is that the rate of change of gene frequency is the resultant of migration, which will tend to decrease the change, and selection acting differentially on the two phenotypes, which will tend to increase it. For an equilibrium situation these two forces must be equal, and hence Haldane is able to derive an expression for the relation between the intensity of selection, the mean distance migrated per generation, and the slope of the cline. Haldane's calculation is in terms of the relative advantages (= fitness in his terminology) of the 
two phenotypes, and the random dispersal distance $(m)$. The assumptions used in making this model are necessarily simplified and formalised, but they seem to be sufficiently realistic to enable us to test whether our data conform to Haldane's theory. It should be emphasised that the assumptions of both Haldane in making the theory and ourselves in presenting the data in the form of fig. 2 (particularly sampling errors, and the difficulty of resolving the distance of places apart to a single dimension), are such that any correspondence between the two must inevitably be approximate. Further, reservations must be entered about two of the assumptions used by Haldane:

I. A. glareosa was common wherever we sampled on its correct habitat (heather). On areas away from the heather it was relatively uncommon; on the serpentine of Unst it was very common. Hence it is not quite correct to assume that "the density is equal throughout the area ".

2. Our assumption of a "sharp division of the area of the species by a straight boundary" is based upon a posteriori evidence. There can be no doubt about the existence of a barrier in the central Mainland of Shetland, but we never anticipated this until we had sampled the populations at a number of places.

Bearing these two reservations in mind, it is possible to test whether our data conform to Haldane's theory. In order to do this we must assume a value for $m$ and then we can test the goodness of fit of Haldane's model to our figures.

Haldane states a relationship between the distance where the frequency of the recessive gene $(y)$ is 25 per cent. and 75 per cent. (the interquartile range) and the fitness of the phenotypes. In the observed data the interquartile range is about 48 miles and hence

$$
k=\frac{\mathrm{I} \cdot 27 m}{4^{8}}
$$

(where $\mathrm{I} \cdot 27$ is Haldane's constant when both quartiles are on the same side of the barrier). Now we have as yet no accurate estimate of $m$, but if we take it as 0.25 miles as the mean for both phenotypes' then

$$
k=0.00004 .
$$

Choosing a value of $K$ which puts $y$ at 90 per cent. at the barrier (see fig. 2), we can now test the observed data against Haldane's model. The goodness of fit was calculated only for that portion of the species' range north of the Tingwall Valley since the relatively small change in gene frequency to the south means that many models would not depart significantly from the observed values. Then, omitting the figures for Gutcher for obvious reasons, and those for Baltasound for the reason which appears below, we obtain $\chi_{(13)}^{2}=24 \cdot{ }^{\cdot} 6\left(\chi_{(13)}^{2}\right.$ at the 5 per cent. probability level $=22 \cdot 36$ ). Although the fit of the data 
to Haldane's model is not perfect, this seems a reasonable result in the light of the many approximations discussed above. Hence it seems legitimate to assume that the observed cline could be accounted for by making the same assumptions as Haldane and choosing a random migration distance of 0.25 miles. By choosing larger values of $m$, it would be necessary to allow a greater intensity of selection to hold the observed cline in existence, but whatever values we choose, it still appears that there is little over-all differential between the two forms. For example, if

$$
\begin{aligned}
& m=\text { I mile, } k=0.0007, K=0.00063 \\
& m=5 \text { miles, } k=0.0175, K=0.015^{8} .
\end{aligned}
$$

This does not negate the fact that heavy selective visual predation may take place, but it does suggest that any such visual advantage is counter-balanced by an equal disadvantage at some period of the life history.

Release-recapture experiments which enable independent estimates $\left(k^{\prime}\right.$ and $\left.K^{\prime}\right)$ to be made of these advantages are described in the following paper (Kettlewell, $\mathrm{I} 96 \mathrm{I} b$ ). It will be seen that $f$. edda was at approximately $7 \pm 6.5$ per cent. advantage at Baltasound, but that neither form had an advantage over the other in Dunrossness. For the reasons which are set out, these estimates do not provide a good measure of the selective advantages of the two forms. However, they are in reasonable accord with the estimates of $k$ and $K$ obtained from the frequency data. It would be wrong to make any quantitative deductions from these figures, but three points can be made:

I. There is good cause for believing that the environment of $A$. glareosa on Muckle Heog (Baltasound) is different from that of the rest of Shetland, with the possible exception of Fetlar (Kettlewell, 1961 $b$ ).

2. The calculated value of $k$ is based upon the whole range of the species north of the Tingwall Valley, but the observed value of $y$ at Baltasound is significantly lower than the one expected if Haldane's model can be applied exactly.

3. Both $K$ and $K^{\prime}$ are small.

The tentative conclusion to be drawn from this is that the conditions for the moth in north Shetland may be such as to alter the relative advantages of the two forms, but over the rest of Shetland there is very little over-all difference between them. However, since the selective differential is so small, there may well be other factors that materially affect the level and stability of the cline. Indeed there must be some factor other than those already discussed to account for the reversal of the differential survival rates to the north and the south of the Tingwall Valley. It is therefore in place to consider other factors that may be involved in the cline. 
I. It has been shown that $f$. edda from Unst have behaviour differences as well as colour differences from south Shetland $f$. typica (Kettlewell, I96I $b$ ). Because of the former it could be that $f$. typica is at a reproductive advantage in regions of certain gene frequencies whilst being at a cryptic disadvantage in the same area.

2. De Ruiter (1952) has shown that when a bird has experienced a particular cryptic insect as an article of food it subsequently tends to search for others of the same model. Cain and Sheppard (I954) have pointed out that if one can conclude from this that the exploitation of one form decreases for a time the chance of finding another, then in a polymorphic species the more abundant form will be proportionately more heavily predated. Hence the uncommon forms would be at an advantage because of their scarcity. If the habits of $f$. edda and $f$. typica are distinct from the predators' point of view, it might be beneficial to the species for both forms to occur together. Such an effect would contribute to the cline, and is not contrary to any of the assumptions involved in making the mathematical model.

3. There is some slight evidence that mating is non-random, and that there is a tendency for opposite phenotypes to pair. Sheppard (I953) has described such an effect in the moth Panaxia dominula L. and he pointed out that this could be at least one of the factors tending to ensure stability in a polymorphism.

4. A balanced polymorphism results if the heterozygotes are at an advantage over both homozygotes. We have no evidence about the presence or absence of any heterosis.

This discussion of the cline has assumed that Haldane's model can be applied. Haldane only considers in detail the case of a species divided by a "sharp boundary". Professor Haldane has pointed out to us that in his theory he assumes only a "boundary", not a barrier to random or other migration. He suggests that the Tingwall Valley may be perhaps as effective as ten miles of heather, and hence the selective intensities may be greater than we have calculated. It is possible that the effects of a gradual change of conditions over the length of Shetland are imposed as well. The fact that $f$. edda also occurs (but at a low frequency) both on Fair Isle to the southwest and Orkney to the south, is in favour of this. This much can be said, however, we have observed no obvious major ecological differences between north and south. We have, however, noted minor ones. Over much of the northern half (with the exception of the small outcrops of serpentine) large areas of peat-hag are evident, the degree of erosion depending on the number of sheep grazing, the activity of the local inhabitants in peat digging and the degree of exposure to winds. In south Shetland there is less peat-hag and more rock, and there is also more cultivation. Also at the extreme south there are considerable areas of sand dunes and we found the species here also.

A further and possible relevant observation is that the average 
heather depths which we tested in the extreme north and south were different. Thus on Unst (serpentine) the deepest heather over two stretches of 200 yards each, sampled at points taken at Io yard intervals, was $\mathrm{I} \cdot 6$ inches. On each occasion the deepest heather available within one yard of the point was chosen, this probably being the greatest distance $A$. glareosa would walk after alighting before taking up a resting position. Using the same methods in the south the mean depth was 3.8 inches. Furthermore, over much of north Mainland and Yell we found that the surfaces of exposed peat, uncovered by vegetation, were much more extensive than in the south.

$F$. edda is highly cryptic resting on peat, whilst $f$. typica is not, unless covered with vegetation. These two factors-depth of vegetation and bare peat surfaces-may in fact play an important role in determining a differential cryptic efficiency between the two forms.

In the absence of more definite and obvious ecological differences between the north and south Shetland, it seems best therefore to accept, with reservations, the application of Haldane's model for the present and the implications that follow from it.

It is worth while to mention the example used by Haldane (I 948) to illustrate his theory of a cline. He considered a cline of de-pigmentation in the deer-mouse, Peromyscus polionotus, described by Sumner (1932), and he found low values of $K$ and $k$. From this he concluded that the mutant variety was "probably formed under the action of much more intense selection on the beaches" (the extreme of its range). This is interesting because we have to postulate much the same effect for the cline in $f$. edda, but here we have obtained the additional information that there is more intense selection operating at the extreme of its range in Unst. This is discussed more fully in the following paper.

In conclusion it is pertinent to point out specifically that the method of analysis of the polymorphism described in this paper is powerless to indicate the actual forces of selection involved. These may in fact be very strong and work in opposing directions: the frequency data reveal only the average conditions of the species throughout its life and the mean selective coefficients which contribute to the polymorphism.

\section{SUMMARY}

1. The moth Amathes glareosa Esp. exists in a dimorphic state in the Shetland Islands, the typical form occupying $9^{8}$ per cent. of the population at the south of the group and being progressively replaced by a distinct melanic form, edda, in a northerly direction so that 97 per cent. of the population is $f$. edda at the north of the group.

2. Population samples were taken at over twenty places throughout the islands, and the gene frequencies from north to south plotted. A frequency map was constructed from over 20,000 moths caught.

3. It was found that a model for a cline suggested by J. B. S. Haldane appeared to fit the data with certain exceptions. Hence it 
was possible to calculate the selective forces necessary to maintain the cline in being, assuming a random dispersal distance of the moths.

4. The selection coefficients involved in the cline are small although the biological pressures are high, but these do not differ significantly from independent estimates of differential selection between the two forms of the moth obtained by release-recapture experiments. Hence it is possible that the cline is maintained entirely by differential predator selection, although it is unlikely that this is so.

Acknowledgments.-We are grateful to Professor J. B. S. Haldane, F.R.s., for his discussion and help on the problem. We wish to thank our co-workers in the field for their part in this work : Dr Caroline Berry, Messrs C. J. Cadbury, T. Peet and G. C. Phillips, and also Mr J. Maynard Smith of University College, London, for his help in the analysis and discussion of the results. Our thanks are due to many Shetlanders, without whose collaboration this work could not have been undertaken. Dr E. B. Ford, F.R.s., Professor H. Grüneberg, F.R.s., and Dr P. M. Sheppard, read the paper in manuscript and made constructive comments, for which we are most grateful. Mr A. J. Lee drew the figures.

We were enabled to do this work because of the generous financial help of the Department of Industrial and Scientific Research (H.B.D.K. and C.J.C.), the Medical Research Council (R.J.B.) and the Nature Conservancy (G.C.P.).

\section{REFERENCES}

Gain, A. J., AND sheppard, P. м. 1954. Natural selection in Cepæa. Genetics, 39, 89-II6.

DE RUITER, L. 1952. Some experiments on the camouflage of stick caterpillars. Behaviour, 4, 222-232.

FFENNELL, D. W. H. I96I. Personal communication.

FISHER, R. A. I950. Gene frequencies in a cline determined by selection and diffusion. Biometrics, $6,353-36 \mathrm{I}$.

haldane, J. B. s. 1948. The theory of a cline. 7. Genet., 48, 277-284.

HARDY, D. E. I96I. Personal communication.

KeTtLEWELL, H. B. D. 1955. Selection experiments on industrial melanism in the Lepidoptera. Heredity, 9, 323-342.

KetTLEWELl, H. в. D. I $961 a$. Geographical melanism in the Lepidoptera of Shetland. Heredity, $16,393-402$.

Kettlewell, H. B. D. $196 \mathrm{I} b$. Selection experiments on melanism in Amathes glareosa, Esp. Heredity, $16,415-434$.

SHEPPARD, P. M. 1953. Polymorphism and population studies. Symp. Soc. exp. Biol., 7, 274-289.

SUMNER, F. B. 1932. Genetic, distributional and evolutionary studies of the subspecies of deer mice (Peromyscus). Biblio. Genet., 9, 1-106. 